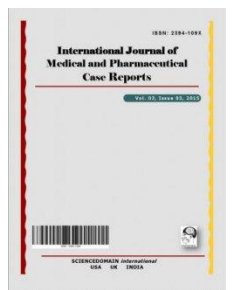

International Journal of Medical and Pharmaceutical
Case Reports

9(3): 1-4, 2017; Article no.IJMPCR.34110

ISSN: 2394-109X, NLM ID: 101648033

\title{
Tyrosine Kinase Inhibitor Induced Pulmonary Artery Hypertension: Reversible with Ponatinib?
}

\author{
Serkan Gokaslan ${ }^{1 *}$, Ersel Onrat $^{1}$, Cigdem Özer Gokaslan ${ }^{2}$ \\ and Ibrahim Etem Dural ${ }^{1}$
}

${ }^{1}$ Department of Cardiology, Faculty of Medicine, Afyon Kocatepe University, Afyonkarahisar, Turkey ${ }^{2}$ Department of Radiology, Faculty of Medicine, Afyon Kocatepe University, Afyonkarahisar, Turkey.

Authors' contributions

This work was carried out in collaboration between all authors. All authors read and approved the final manuscript.

Article Information

DOI: 10.9734/IJMPCR/2017/34110

Editor(s):

(1) Syed A. A. Rizvi, Department of Pharmaceutical Sciences, College of Pharmacy, Nova Southeastern University, USA.

Reviewers:

(1) Ramachandran Muthiah, Thoothukudi Medical College Hospital, Thoothukudi, India.

(2) Arthur Nwafor Chuemere, University of Port Harcourt, Nigeria.

(3) L. I. Audu, National Hospital Abuja, University of Abuja, Nigeria.

Complete Peer review History: http://www.sciencedomain.org/review-history/19497

Case Study

Received $14^{\text {th }}$ May 2017

Accepted $8^{\text {th }}$ June 2017

Published 12 ${ }^{\text {th }}$ June 2017

\begin{abstract}
Pulmonary arterial hypertension (PAH) is a disease associated with progressive and comprehensive vascular remodeling of small pulmonary arteries. The prognosis of Chronic myelogenous leukemia $(\mathrm{CML})$ has been improved by tyrosine kinase inhibitors (TKIs), which inhibit BCR/ABL kinase pathway. Most of the TKIs induced PAH is limited almost exclusively to dasatinib until now. There was only one report about, PAH was caused by the novel TKI ponatinib. We present a 73 years oldfemale patient with chronic myeloid leukemia, who had PAH after approximately 72 months with prior exposure to dasatinib. Dasatinib was replaced by nilotinib in this patient. Nilotinib was used 11 months for CML treatment, but no recovery was seen with also this TKI. Finally, ponatinib therapy was started for CML. Signs and symptoms of PAH improved with institution of ponatinib therapy. Therefore we report that the patient with dasatinib induced PAH did not recover after institution of nilotinib as a TKI instead of dasatinib but improved with ponatinib treatment using for CML.
\end{abstract}

${ }^{*}$ Corresponding author: E-mail: serkangokaslan6@gmail.com; 
Keywords: Chronic myelogenous leukemia (CML); Tyrosine kinase inhibitors (TKIs); Pulmonary arterial hypertension $(P A H)$.

\section{INTRODUCTION}

Pulmonary arterial hypertension (PAH) is a disease associated with progressive and comprehensive vascular remodeling of small pulmonary arteries. The remodeling process is the result of cellular hypertrophy, hyperplasia, apoptosis, inflammation and deposition of extracellular matrix. Vascular remodeling includes medial hypertrophy, muscularization of small arterioles, intimal thickening, and the formation of plexiform lesions [1].

Chronic myelogenous leukemia (CML) is a chronic myeloproliferative disorder characterized by a translocation between chromosome 9 and 22. This translocation pathogenically leads to a tyrosine kinase signal transduction protein, the breakpoint cluster region/Abelson (BCR/ABL). The prognosis of CML has been improved by tyrosine kinase inhibitors (TKIs), which inhibit $\mathrm{BCR} / \mathrm{ABL}$ kinase pathway, such as imatinib. However up to now, $20 \%$ of imatinib treated patients with CML cannot achieve full cytogenetic response. Data suggest that, 2 new TKIs, dasatinib and nilotinib are associated with higher rates of full cytogenetic response in newly diagnosed and imatinib-resistant chronic phase CML $[2,3]$.

The TKIs, imatinib, dasatinib, nilotinib and bosutinib are associated with significant respiratory adverse effects, including pleural and/or pericardial effusion. $\mathrm{PAH}$ is a rare adverse effect of TKls. Most of the TKIs induced PAH is limited almost exclusively to dasatinib until now [4,5-7]. There was only one report of PAH caused by the novel TKI ponatinib [8].

\section{CASE REPORT}

We present a 73 years old-female patient with chronic myeloid leukemia, who had PAH after approximately 72 months of prior exposure to dasatinib. Dasatinib was replaced by nilotinib in this patient. Nilotinib was used for 11 months for CML treatment, but no recovery was seen with also this TKI. Finally, ponatinib therapy was started for CML. Signs and symptoms of PAH improved with institution of ponatinib therapy.

CML was diagnosed in 2009. Furthermore she had moderate systemic hypertension and atrial fibrilation. She was on long-term treatment with ramipril, hidroclorothiazid, digoksin and apixaban for these cardiac diseases. She has been treated with dasatinib (100 mg once daily in 2009-2015), then nilotinib (400 mg twice daily in August 2015July 2016). Finally ponatinib (30 mg once daily) was started in July 2016.

In August 2015, she had dyspnea with New York Heart Association (NYHA) class III-IV. The workup for dyspnea included transthorasic echocardiography disclosed right ventricular dilatation and systolic pulmonary artery pressure (sPAP) was estimated at $70 \mathrm{mmHg}$. The NTproBNP was $1650 \mathrm{pg} / \mathrm{ml}$. No thromboembolism evidence existed but dilatation of pulmonary trunk and proximal arteries was found on chest computed tomography scan. Rheumatology and chest disease consultation didn't show any other $\mathrm{PAH}$ causes except drug induced $\mathrm{PAH}$ (associated with TKIs). Dasatinib was replaced by nilotinib because of dasatinib induced $\mathrm{PAH}$ suspicion.

She took nilotinib between August 2015 and July 2016. The patient had dyspnea with NYHA class III-IV and NT-proBNP was $1605 \mathrm{pg} / \mathrm{ml}$. Transthorasic echocardiography disclosed right ventricular dilatation and SPAP was estimated at $75 \mathrm{mmHg}$ so no recovery was seen with nilotinib after 11 month therapy. On both treatments, the patient did not take any PAH medication.

Nilotinib was stopped and ponatinib therapy was commenced in August 2016. After 6 monthstherapy with ponatinib, dyspnea improved and the patient's NYHA class became class II. The NT-proBNP was $1351 \mathrm{pg} / \mathrm{mL}$. Echocardiogram disclosed mild right ventricular dilatation and systolic pulmonary artery pressure (sPAP) was estimated at $50 \mathrm{mmHg}$ without any $\mathrm{PAH}$ medication. At this time, PAH therapy clinic was founded and right-sided catheterization was done. Precapillary pulmonary hypertension with a mean PAP of $33 \mathrm{mmHg}$ and normal pulmonary wedge pressure of $12 \mathrm{mmHg}$ was determined. PAH specific treatment was started to the patient in our cardiology clinic.

\section{DISCUSSION}

There are increasing number of case reports about dasatinib induced PAH in CML patients [912]. Quinta's-Cardama et al. reported the first case of dasatinib associated PAH in 2007 [13]. In 
2012, nine dasatinib induced $\mathrm{PAH}$ cases have been identified [5]. In the literature, although there were much more dasatinib induced $\mathrm{PAH}$, only one case was reported with elevation of the pulmonary artery pressure attributed nilotinib [14].

$\mathrm{PAH}$ appears to be a late complication of dasatinib, usually occurs after 8-48 months of exposure. In the majority of cases, symptoms are improved after discontinuation of dasatinib, but some cases require $\mathrm{PAH}$-specific therapy with sildenafil [9]. In present case, dasatinib induced $\mathrm{PAH}$ detected on $72^{\text {nd }}$ month of treatment. Dasatinib was switched to nilotinib. Pulmonary artery pressure did not decrease with nilotinib therapy during 1 year nilotinib therapy period. The NT-proBNP and NYHA Class were high on both of dasatinib and nilotinib therapy periods. During nilotinib therapy we lost the patient follow up. Patient did not have any benefit or harmful effect on pulmonary artery pressure level during nilotinib therapy period. After one year using nilotinib, pulmonary artery pressure measured by echocardiography increased only $5 \mathrm{mmHg}$. But this increase can be operator variability. With these findings we cannot say nilotinib caused $\mathrm{PAH}$. Because before nilotinib therapy, $\mathrm{PAH}$ has already occured during dasatinib therapy. During 7 years, no PAH specific therapy was given to because of lack of PAH specific department in our hospital.

We found only one $\mathrm{PAH}$ case with the use of ponatinib in the literature like nilotinib $[8,14]$. Despite the fact that, only one patient with pulmonary hypertension was reported with ponatinib therapy in the literature, we found a decrease in pulmonary hypertension findings, NTproBNP level and pulmonary artery pressure measured by echocardiography on the $6^{\text {th }}$ month, after nilotinib therapy switched to ponatinib in the patient.

The previous studies showed the link between NT pro BNP levels and right ventricular function in patients with pulmonary arterial hypertension [15]. Increased plasma levels of NT-proBNP were associated with worse prognosis, while decreasing plasma level indicates successful management of pulmonary hypertension [16].

\section{CONCLUSION}

Our findings and pulmonary artery pressure decreasing with ponatinib therapy after dasatinib and nilotinib is very impressive in this case presentation. Therefore we report that the patient with dasatinib induced $\mathrm{PAH}$ did not recover after institution of nilotinib as a TKI instead of dasatinib but improved with ponatinib treatment used for CML.

\section{CONSENT}

As per international standard or university standard, patient's written consent has been collected and preserved by the author(s).

\section{ETHICAL APPROVAL}

As per international standard or university standard written ethical approval has been collected and preserved by the author(s).

\section{COMPETING INTERESTS}

Authors have declared that no competing interests exist.

\section{REFERENCES}

1. Humbert M, Morrell NW, Archer SL, et al. Cellular and molecular pathobiology of pulmonary arterial hypertension. J Am Coll. Cardiol. 2004;43(12, Suppl S): 13S-24S.

2. Kantarjian $H$, Shah NP, Hochhaus $A$, Cortes J, Shah S, Ayala M, Moiraghi B, Shen Z, Mayer J, Pasquini R, Nakamae H, Huguet F, Boque C, Chuah C, Bleickardt E, Bradley-Garelik MB, Zhu C, Szatrowski T, Shapiro D, Baccarani M. Dasatinib versus imatinib in newly diagnosed chronic-phase chronic myeloid leukemia. N Engl J Med. 2010;362:2260-2270.

3. Saglio G, Kim DW, Issaragrisil S, le Coutre P, Etienne G, Lobo C, Pasquini R, Clark RE, Hochhaus A, Hughes TP, Gallagher $N$, Hoenekopp $A$, Dong $M$, Haque $A$, Larson RA, Kantarjian HM. Nilotinib versus imatinib for newly diagnosed chronic myeloid leukemia. $N$ Engl J Med. 2010;362:2251-2259.

4. Camus P. Pneumotox II. The drug-induced respiratory disease. 2012;(V2.0).

Available:www.pneumotox.com

(Date last accessed: December 17, 2015.) (Date last updated: December 1, 2015.)

5. Montani D, Bergot E, Günther $S$, et al. Pulmonary arterial hypertension in patients treated by dasatinib. Circulation. 2012; 125:2128-2137. 
6. Breccia M, Alimena G. Occurrence and current management of side effects in chronic myeloid leukemia patients treated frontline with tyrosine kinase inhibitors. Leuk Res. 2013;37:713-720.

7. Cortes J, Mauro M, Steegmann JL, et al. Cardiovascular and pulmonary adverse events in patients treated with $B C R-A B L$ inhibitors: Data from the FDA adverse event reporting system. Am $\mathrm{J}$ Hematol 2015;90:E66-E72.

8. Quilot FM, Georges M, Favrolt N, Beltramo G, Foignot C, Grandvuillemin A, Montani $D$, Bonniaud $P$, Camus $P$. Pulmonary hypertension associated with ponatinib therapy. Eur Respir J. 2016;47(2):676-9.

9. Orlandi EM, Rocca B, Pazzano AS, Ghio S. Reversible pulmonary arterial hypertension likely related to long-term, low-dose dasatinib treatment for chronic myeloid leukaemia. Leuk Res. 2012;36(1):e4-e6.

10. Dumitrescu D, Seck $C$, ten Freyhaus $H$, Gerhardt F, Erdmann E, Rosenkranz S. Fully reversible pulmonary arterial hypertension associated with dasatinib treatment for chronic myeloid leukaemia. Eur Respir J. 2011;38(1):218-220.

11. Mattei D, Feola M, Orzan F, Mordini N, Rapezzi D, Gallamini A. Reversible dasatinib-induced pulmonary arterial hypertension and right ventricle failure in a previously allografted CML patient. Bone Marrow Transplant. 2009;43(12):967-968.

12. Rasheed W, Flaim B, Seymour JF. Reversible severe pulmonary hypertension secondary to dasatinib in a patient with chronic myeloid leukemia. Leuk Res. 2009; 33(6):861-864.

13. Quintas-Cardama A, Kantarjian H, O'Brien S, Borthakur G, Bruzzi J, Munden R, et al. Pleural effusion in patients with chronic myelogenous leukemia treated with dasatinib afterimatinib failure. J Clin Oncol 2007;25:3908e14.

14. Zakrzewski D, Seferynskal, Warzoch K, Hryniewiecki T. Elevation of pulmonary artery pressure as a complication of nilotinib therapy for chronic myeloid leukemia. Int J Hematol. 2012;96(1):132135.

15. Overbeek MJ, van Nieuw Amerongen GP, Boonstra A, Smit EF, Vonk-Noordegraaf A. Possible role of imatinib in clinical pulmonary veno-occlusive disease. Eur Respir J. 2008;32:232-5.

16. Williams $\mathrm{MH}$, Handler $\mathrm{CE}$, Akram $\mathrm{R}$, Smith CJ, Das C, Smee J, Nair D, et al. Role of $\mathrm{N}$-terminal brain natriuretic peptide $(\mathrm{N}$ TproBNP) in scleroderma-associated pulmonary arterial hypertension. Eur Heart J. 2006;27:1485-94.

(c) 2017 Gokaslan et al.; This is an Open Access article distributed under the terms of the Creative Commons Attribution License (http://creativecommons.org/licenses/by/4.0), which permits unrestricted use, distribution, and reproduction in any medium, provided the original work is properly cited.

Peer-review history:

The peer review history for this paper can be accessed here: http://sciencedomain.org/review-history/19497 